\title{
Case study in training of diagnostics of mechanisms of psychological defense in a conflict situation
}

\author{
Nadezhda Sivrikova ${ }^{1, *}$, Tatyana Ptashko ${ }^{2}$, Elena Chernikova $^{2}$, Artem Perebeynos $^{2}$, \\ Svetlana Roslyacova ${ }^{2}$ and Elena Moiseyeva ${ }^{2}$ \\ ${ }^{1}$ South Ural State Humanitarian Pedagogical University, Department of Social Work, Pedagogy and \\ Psychology, Chelyabinsk Lenin prospect 69, Russia \\ ${ }^{2}$ South Ural State Humanitarian Pedagogical University, Department of Social Work, Pedagogy and \\ Psychology, Chelyabinsk Lenin prospect 69, Russia
}

\begin{abstract}
The relevance of a research is dictated by need of training of specialists in the field of management of the conflicts. Researchers recognize need of development of skills of overcoming barriers of effective resolution of conflicts. Defense mechanisms are such barriers. Creation a case study of training of definition of defense mechanisms in a conflict became a research objective. First, cases of video were created. Secondly, the scheme of the analysis of manifestations of mechanisms of protection in the conflict was created. The created cases were used for training of future specialists in management of the conflicts (23 people). The experimental plan with pre-post-testing and control group (13 people) was used for approbation of the created case study. Results of approbation a case study showed that it is an effective technique of formation of skills of definition of defense mechanisms in a conflict situation.
\end{abstract}

\section{Introduction}

Researchers all the world note that training in management of the conflicts is important for peaceful co-existence of people [1]. Students of the helping professions speak about importance of ability to operate the conflicts: doctors [2] and nurses [3], HR managers [4], etc. Russian teachers [5] speak about necessity of formation of conflictological competence at all students irrespective of specialty. Foreign researchers say that competences in resolution of conflicts bring benefit during all human life [6,7]. They specify that training courses on management of the conflicts have to be included in curricula of institutions of higher education, institutes of training of teachers and the program of professional development [8].

On the one hand, it is connected with the fact that experts recognize inevitability, naturalness of the conflicts in communication between people, and on the other hand, experts recognize constructive role conflicts in development of the relations and the personality.

\footnotetext{
* Corresponding author: bobronv@,cspu.ru
} 
Thus, in the modern world focus of attention addresses to the questions of effective resolution of conflicts, using of their positive potential in work, creativity, study. Efforts of experts are directed to development of technologies of effective reconciliation in conflict situations. An example of such technology is mediation. It represents structural process in which the neutral and impartial third party (mediator) helps two or more people to agree about settlement of the conflict [7].

Empirical data show that training of technology of mediation of pupils of middle and high school contributes to the development of their communicative skills, empathy, increase in a self-assessment and improvement of progress $[8,9]$. Introduction of programs of training of mediation and resolution of conflicts has a great influence on adaptation of studying [10], psychological climate at school [11]. Theoretical and empirical researches allow to draw a conclusion that practice of mediation has a positive impact on emotional wellbeing of a mediator [8].

At the same time, foreign researchers note that use of mediation as priority, though not exclusive, strategists of management and resolution of conflicts in the growing number of contexts tends to cause big expectation concerning their potential efficiency. It is worth recognizing that effective in permission of certain types of the conflicts, this technology not always allows to achieve positive results [12]. Therefore, studying of barriers which reduce efficiency of mediation is important.

\section{Statement of a problem}

Foreign researchers consider the factors interfering successful mediation, rooting in cognitive and social psychology $[12,13,14]$. Rigid beliefs and emotions which promote the selective, prejudiced and distorted information processing [14]; fundamental error of attribution, jet devaluation [13]; stereotypes and prejudices [12] call barriers to reconciliation of the conflicting parties. Foreign psychologists seek to estimate efficiency classical the technician and receptions in fight against these barriers [15]. Special attention is paid to a role of emotions in emergence and resolution of conflicts $[16,17]$.

Emotional manifestations of the personality in conflict interaction are analysed by Russian researchers [18]. L.G. Ageeva specifies that the conflicts have the psychological component which is shown in the nature of experiences of the personality, emotional maintenance of the conflicts. Because of emotions conflicting parties risk to leave from the solution of a problematic issue and will switch to mutual reproaches and insults that interferes with reconciliation and aggravates contradictions [18]. Therefore, much attention is paid to work with emotions in the course of mediation.

Any conflict situation is followed by negative emotions (irritation, anger, aggression, offense, etc.) of conflicting parties. Regulation of these emotions mostly is carried out unconsciously that can become an obstacle for constructive resolution of conflict. A striking example of such regulation are mechanisms of psychological defense.

According to R. Plutchik's theory, defense mechanisms are derivative of emotions and are consecutive distortion of cognitive and affective components of an image of a real situation with the purpose of weakening of the emotional pressure menacing to the individual in case the situation is reflected in compliance, extremely possible for the individual, with reality of [19]. Therefore, the main objective of mechanisms of psychological defense of the personality consists in regulation of negative emotions (first of all decrease in level of alarm), due to distortion of processes of reception, processing and storage of information.

The emotions accompanying the conflict indicate psychological discomfort of the personality of which the personality tries to get rid, using mechanisms of psychological defense. At the same time the person can ignore separate elements of a conflict situation 
(denial), or replace the object causing emotions on safer (replacement), or to think out justifications of the behavior (rationalization), etc. In such conditions to reach reconciliation it becomes impossible. Researches show that mechanisms of psychological defense of the personality: most intensively participate at emergence and permission of a conflict situation [20], help to transform the conflict of tasks to the conflict of the relations [21] and the internal conflict into interpersonal promote [22].

Poorly realized nature of defense mechanisms transfers this class of barriers of effective resolution of conflicts to group of the most dangerous. However, in spite of the fact that operation of defense mechanisms is hidden from consciousness of the person using them on condition of special preparation, becomes obvious to the third part - the observer.

Thus, theoretical and empirical researches allow to draw a conclusion that mechanisms of psychological defense of the personality can interfere with peaceful resolution of the conflicts, but existence of the impartial third part in the course of mediation opens opportunities for effective work with barriers of this sort.

Mechanisms of psychological defense of the personality in the course of resolution of conflict (mediation) became an object of this research. Manifestations of psychological defense of the personality in the course of mediation, their role in permission of conflict situations remain poorly studied in science. There is a problem of diagnostics of defense mechanisms in the course of mediation. Therefore, we used a qualitative method of the research (Case method) for obtaining the fullest information on the studied phenomenon at the initial stage of its studying. It represents a method of extraction of a concrete perspective from concrete practice and its representation in the form of the oral description, the text.

The choice a case method for studying of mechanisms of psychological defense of the personality in the course of mediation is dictated by polyfunctionality of this method. The cases developed during the research allow to solve not only diagnostic problems. They can be used for training of mediators and assessment of formation at them necessary competences.

\section{Research purpose}

To develop and approve in practice a case method of training in bases of definition of mechanisms of psychological defense of the personality in the course of mediation.

\section{Method}

The analysis of educational mediations (a case method) became the main method of a research. The offer to comprehend (to analyse) a certain situation which description at the same time reflects not only any practical problem but also updates a certain complex of knowledge which needs to be shown (to acquire) at permission of this problem is the cornerstone of a case method. The case contains exhaustive information on what occurs who participates in it in what conditions events are developed, etc.

Within the research the structure of a case was developed for the analysis of manifestations of mechanisms of psychological defense of the personality in the course of mediation. It included: short description of a conflict situation; conflicting parties; markers (behavioural manifestations) of uneasiness, tension; a name of the hero who is alarmed; the description of threat (imaginary or real) for "Ego" the hero feeling mental strain; the mechanism of psychological defense reducing the level of uneasiness of the hero.

For approbation of the developed structure of a case 35 fragments of movies in which the interpersonal conflicts were shown were selected. These 35 rollers were analyzed by the 
expert group including 1 mediator, 3 psychologists and 4 teachers. Each expert described the conflict shown in the offered movies according to the developed structure of a case. Its results were discussed by all experts in common. 16 cases for development of skills of diagnostics of mechanisms of psychological defense in the conflict and estimates of the level of development of these skills were as a result created.

The developed cases were used for training in diagnostics of psychological protection of the personality in the conflict of masters-mediators (10 people), during the special training. They were used as means of assessment of level of formation of conflictological competence at the students-conflictologists studying according to the program of a bachelor degree (13 people). Students of faculty of psychology (13 people) acted as control group. Kruskal-Wallis test and was Wilcoxon test used for mathematical processing of empirical data.

\section{Results}

Video-cases for training of students in bases of definition of psychological defense of the personality in a situation of the interpersonal conflict was prepared at the first investigation phase.

The basis of structure of a case was formed by ideas of a subject (what protects?), an object (the nature of the threat demanding protection inclusion), ways (how protection will be organized?) and results (what protection leads to?) psychological defense of the personality. Different theorists allocate with different sense, these provisions. Within this article there is no opportunity for the detailed analysis of the different points of view. But it is possible to allocate the most general moments. The most general opinion consists that a subject of psychological defense is idea of itself and the world, in a conflict situation (internal or external). Authors agree that psychological defense is intended to save the person from alarm (object to protection). The mechanisms of psychological defense allocated by different authors, are, actually, means of defense. There are disagreements in the points of view of different authors apropos result of psychological defense. Generally, they are connected with allocation of near and far object of psychological defense, and, therefore, in the most general view it is possible to speak both positive and negative result of psychological defense. The psychological specifics are caused by the protection subject of nature (subjective representation) and also means as the symbolical actions making changes not so much in the real objective world, as in the world of subjective values and meanings.

Thus, the structure of a case (the scheme of the analysis) for the description of the mechanism of psychological protection of the personality in a conflict situation must to consist from:

1. The short description of a situation in a free form.

2. Transfer of conflicting parties (between whom and who develops the conflict).

3. The description of the causes of conflict (because of what there is an opposition that cannot divide party of the conflict).

4. Markers (behavioural manifestations) of uneasiness, nervous tension at the hero and a name of the hero who experiences strong negative emotions.

5. The description of threat (real or imaginary) for "I" the hero feeling strong mental strain.

6. The description of the mechanism of psychological protection of the personality reducing the level of uneasiness of the hero.

It was offered to group of experts to describe 35 fragments taken from Russian and foreign movies on specially developed scheme. When choosing fragments the following parameters were considered: duration of a fragment has to be no more than 5 minutes, 
representation in a fragment of the causes of conflict and reactions (verbal and nonverbal) all participants of the conflict, an opportunity to make idea of the causes of conflict. In results fragments from such movies as were selected: Office romance, the Twist of fate or with light steam, the Bachelor, Pride and prejudice.

8 experts described each video case independently. And then discussed results of the work among themselves. 16 educational cases were as a result created. These are fragments of movies by which experts managed to reach full consent. Results of the done work showed that in conflict situations there is tension in connection with assessment of the situation as the personality menacing "Ego". To lower internal alarm people unconsciously use mechanisms of psychological defense. It complicates a conflict situation, interfering with its peaceful resolution.

Therefore, the created cases were used for training of future mediators (students of a magistracy) and of future conflictologists (students of a bachelor degree) in bases of definition of mechanisms of psychological defense of the personality in a situation of the interpersonal conflict. Future mediators were trained within the seminar training "Psychological defense of the personality". On a training they studied bases of definition of protective mechanisms (with the help a case method), features of manifestation of own protective mechanisms (by means of projective techniques), ways of the analysis of the intra personal conflicts, the strategy of work with psychological protection of the personality in a conflict situation. Students-conflictologists studied manifestations of mechanisms of psychological defense of the personality in the conflict only by means of the developed cases within one of subject matters.

Before and after training of students it was offered to define the mechanisms of psychological defense used by heroes of feature films in a conflict situation. Results of performance of a task were estimated to a 6 ball system.

The definitions of mechanisms of psychological protection of the personality given about approbation of a technique of training in bases in a conflict situation on a basis of a case method presented in table 1 .

Table 1. The level of development of skills of definition of mechanisms of psychological protection of the personality in a conflict situation before training.

\begin{tabular}{|c|c|c|c|c|c|}
\hline \multirow[b]{2}{*}{$\begin{array}{l}\text { Distribution } \\
\text { parameters }\end{array}$} & \multicolumn{3}{|c|}{ The compared groups } & \multirow{2}{*}{$\begin{array}{l}\text { Kruskal - } \\
\text { Wallis test } \\
\text { (Chi-Square) }\end{array}$} & \multirow{2}{*}{$\begin{array}{l}\text { Asymptotic } \\
\text { significant } \\
\text { (2-sided) }\end{array}$} \\
\hline & $\begin{array}{l}\text { masters- } \\
\text { mediators }\end{array}$ & $\begin{array}{l}\text { students- } \\
\text { conflictologists }\end{array}$ & $\begin{array}{l}\text { students- } \\
\text { psychologists }\end{array}$ & & \\
\hline number & 10 & 13 & 13 & \multicolumn{2}{|l|}{ Test Statistics } \\
\hline \multicolumn{6}{|c|}{ Results of execution of the test BEFORE training } \\
\hline $\begin{array}{l}\text { average value } \\
\text { on group } \\
\text { (point) }\end{array}$ & 1.80 & 1.38 & 1.23 & 1.02 & 0.313 \\
\hline \multicolumn{6}{|c|}{ Results of execution of the test AFTER training } \\
\hline $\begin{array}{l}\text { average value } \\
\text { on group } \\
\text { (point) }\end{array}$ & 5.10 & 2.46 & 1.62 & 16.76 & 0.0001 \\
\hline \multicolumn{6}{|l|}{ Test Statistics } \\
\hline $\begin{array}{l}\text { Wilcoxon } \\
\text { test }(\mathrm{Z})\end{array}$ & -2.85 & -2.558 & -1.667 & & \\
\hline $\begin{array}{l}\text { Asymptotic } \\
\text { significant } \\
\text { (2-sided) }\end{array}$ & 0.004 & 0.011 & 0.096 & & \\
\hline
\end{tabular}

In all studied groups the low level of development of skills of definition of mechanisms psychological protection of the personality at participants of the conflict, according to 
results of assessment of skills of students before carrying out training is observed. At the same time significant distinctions, according to Kruskala-Wallice's test, between the compared groups before training it was revealed not.

After training of masters-mediators and students-conflictologists the level of development of their skills in definition of mechanisms of psychological defense of the personality in a conflict situation significantly increased. In group of masters (who were trained at a seminar training)the intensity of shifts to increase in the studied skills was much higher, than towards decrease $(\mathrm{p}=0.004)$. In group of students-conflictologists (who in the course of training used the cases developed by us) the intensity of shifts towards increase in the studied skills was significantly above, than towards decrease $(p=0.011)$. In control group (psychologists of students) after carrying out a research of significant distinctions it was not succeeded to find. $(\mathrm{p}=0.096)$.

It is possible to note that the level of the studied skills increased in experimental groups, and in control group is not present. At the same time, among future mediators of the loudspeaker of the studied skills it was more intensive, than among future conflictologists. It means that at an integrated approach to training in bases of work with psychological defense of the personality in the conflict her results will be higher.

Thus, we developed an effective technique of training of students in skills of definition of mechanisms of psychological protection of the personality in a conflict situation. Further application a case method for studying of features of manifestation of mechanisms of psychological protection of the personality in the course of mediation is planned.

Restrictions of the presented research are connected with the small volume of selection and use of feature films as bases for training and assessment of skills of students. At the same time, the received results are of interest to mediators and those who are engaged in their training. The developed case method can be used both in training and in researches of behaviour of the person in the conflict.

\section{Conclusion}

Results of a research allowed to draw a conclusion that the case study is an effective remedy of formation of skills of definition of defense mechanisms in a conflict situation.

Results of research showed that the level of skills of definition of defense mechanisms in a situation of the conflicts was equally low in all studied groups before training. Level of the studied skills increased in groups of future mediators and conflictologists after training. At the same time dynamics was higher in the first group, than in the second one. Level of skills of definition of defense mechanisms in a situation of the conflict was left without changes in control group.

It is clear that we must note limitations of the present study. First, because of the small sample size, the present study had only limited power. Second limitation is connected with necessity of formation of equal groups of the people identifying themselves with different generations on volume. Natural elimination of respondents could lead to distortion of results of a research.

\section{References}

1. D. Lacuesta-vizcaino, J. A. Traver-marti, E. 1.Contigo, REICE, 16(1), 53-71 (2018).

2. S.Vandergoot, A.Sarris, N.Kirby, H.Ward, Journal of interprofessional care, 32(2), 211-219 (2018)

3. F. K. Cheng, Nurse Education in Practice, 15, 310-313 (2015)

4. E.A. Karpova,Akmeology, 3, 85 (2015) 
5. A. Bissembayeva, N. Sivrikova, S. Roslyakova, E. Kharlanova,N.Sokolova, E.Moiseeva,V. Zherebkina, Opción, 34(15), 1350-1377 (2018)

6. G. Ciuladiene, R. Raudeliunaite, EDULEARN16: Conference proceedings: 8th International conference on Education and new learning technologies, Barcelona, Spain. IATED Academy, 8915-8923 (2016)

7. G. Ciuladiene, Pedagogika,129(1), 220-233 (2018)

8. C. C. Gayer, S. Landman, E. Halperin, D. Bar-Tal, Journal of Conflict Resolution, 53(6), 951-975 (2009)

9. D.A. Malizia, J.K. Jameson, Conflict resolution quarterly, 35(3), 301-318 (2018)

10. F. Turk, International Education Studies, 11(1), 25-43 (2018)

11. M. M. Ttofi, D. P. Farrington, Journal of Experimental Criminology, 7(1), 27-56 (2011)

12. C. M. Alcover, Revista RUEDA, 2, 57-66, (2018)

13. R. B. Korobkin, Ohio State Journal on Dispute Resolution, 21, 281-238,(2006)

14. D. Bar-Tal, E. Halperin, Conflict \& communication online, 12(2), (2013)

15. S.L.Rogers, J.Howieson, C. Neame, PeerJ , 6, e4831, (2018)

16. V. J.Friedman, D.Arieli, O. Aboud-Armali, Conflict Resolution Quarterly,35(4), 351366 (2017)

17. S.Ibarrola-García, C.Iriarte, M.Aznárez-Sanado, Electronic Journal of Research in Educational Psychology,15(1), 75-105 (2017)

18. L.G. Ageeva, Modern researches of social problems,3-2 (59), 220-227 (2016)

19. E.S.Romanova, L.G.Grebennikov,Mytishchi, Talent (1996)

20. V.G. Kamensk, Moscow, Yurait (2018)

21. S.Q.Zheng, W.Z. Chen, Proceedings Paper: Innovation, entrepreneurship and strategy in the era of internet. Chengdu: Sichuan UNIV press, 976-981 (2016)

22. I.E. Zhmurin, Training Psychology, 1, 122-130 (2018) 